\title{
Perceived Threat, Risk Perception, and Efficacy Beliefs Related to SARS and Other (Emerging) Infectious Diseases: Results of an International Survey
}

\author{
Onno de Zwart • Irene K. Veldhuijzen • Gillian Elam • \\ Arja R. Aro - Thomas Abraham • George D. Bishop • \\ Hélène A. C. M. Voeten • Jan Hendrik Richardus • \\ Johannes Brug
}

Published online: 6 January 2009

(C) The Author(s) 2008. This article is published with open access at Springerlink.com

\begin{abstract}
Purpose To study the levels of perceived threat, perceived severity, perceived vulnerability, response efficacy, and selfefficacy for severe acute respiratory syndrome (SARS) and eight other diseases in five European and three Asian countries.
\end{abstract}

O. de Zwart $(\bowtie) \cdot I$. K. Veldhuijzen $\cdot$ J. H. Richardus Division of Infectious Diseases Control,

Municipal Public Health Service Rotterdam-Rijnmond, P.O. Box 70032, 3000 LP Rotterdam, The Netherlands

e-mail: dezwarto@ggd.rotterdam.nl

O. de Zwart • I. K. Veldhuijzen • H. A. C. M. Voeten •

J. H. Richardus $\cdot$ J. Brug

Department of Public Health, Erasmus MC,

University Medical Center Rotterdam,

Rotterdam, The Netherlands

G. Elam

Health Protection Agency-Centre for Infections,

London, UK

\section{A. R. Aro}

Unit for Health Promotion Research,

University of Southern Denmark,

Esbjerg, Denmark

\section{T. Abraham}

Journalism and Media Study Centre,

The University of Hong Kong,

Hong Kong, Hong Kong

G. D. Bishop

Department of Psychology, National University of Singapore,

Singapore, Singapore

J. Brug

EMGO Institute, VU University Medical Center,

Amsterdam, The Netherlands
Method A computer-assisted phone survey was conducted among 3,436 respondents. The questionnaire focused on perceived threat, vulnerability, severity, response efficacy, and self-efficacy related to SARS and eight other diseases. Results Perceived threat of SARS in case of an outbreak in the country was higher than that of other diseases. Perceived vulnerability of SARS was at an intermediate level and perceived severity was high compared to other diseases. Perceived threat for SARS varied between countries in Europe and Asia with a higher perceived severity of SARS in Europe and a higher perceived vulnerability in Asia. Response efficacy and self-efficacy for SARS were higher in Asia compared to Europe. In multiple linear regression analyses, country was strongly associated with perceived threat.

Conclusions The relatively high perceived threat for SARS indicates that it is seen as a public health risk and offers a basis for communication in case of an outbreak. The strong association between perceived threat and country and different regional patterns require further research.

Keywords Risk perception · SARS · Infectious diseases · Efficacy beliefs $\cdot$ Risk communication .

International comparison

\section{Introduction}

Severe acute respiratory syndrome (SARS) and avian influenza are two examples of recent emerging infectious diseases that may cause severe threats to population health, large economic losses, as well as fear and dread $[1,2]$. The behavior of the general population or specific risk groups 
can play an important role in both the spread and control of infectious diseases. The SARS epidemic showed the impact of worldwide travel on the rapid spread of an epidemic, as well as the possible merits of strict hygiene and quarantine measures in halting that epidemic [3]. In case of an infectious disease pandemic, public health authorities will be dependent on the willingness and ability of the general public to adhere to recommendations regarding personal hygiene, vaccination and/or prophylaxis, quarantine, travel restrictions, or closing down of public buildings such as schools $[4,5]$. Compliance with recommended precautionary behaviors is not self-evident [6]. Specific attention to factors influencing behavioral change during outbreaks of infectious diseases is, therefore, necessary.

One of the factors that may influence willingness and motivation to adopt precautionary behaviors is risk perception [7-10], i.e., the perceived personal vulnerability or likelihood of a disease or health threat. Perceived vulnerability, combined with perceived severity, can be regarded as perceived threat. People are expected to have the highest perceived threat of SARS if they think that an infection with SARS is likely and will have serious health consequences. However, risk perception is certainly not the only determinant of protective behavior. Protection Motivation Theory suggests that response efficacy (i.e., the extent to which people believe that available protective actions against SARS are effective) and self-efficacy (i.e., the extent to which people believe they have the ability to engage in such protective actions) are two other key predictors of protection motivation [8].

Risk perceptions are often biased. Unrealistic optimism about risks is often observed toward familiar risks that are perceived to be largely under volitional control. People perceive their relative risk compared to others of the same gender and age as lower. A pessimistic bias, i.e., perceptions of risk that are (much) higher than actual risk, is more likely for new risks that are perceived as uncontrollable. The latter might be the case with new emerging infectious diseases, like SARS [9-12].

While in some fields, such as environmental risks, risk perception has been studied intensively, not much is known about risk perception of recently emerging infectious diseases. Related to emerging infections diseases, first, explorative and descriptive studies are needed to increase our insights in perceived threat, risk perception, and efficacy beliefs. Such studies can inform more focused and theory-driven investigations. During and in the aftermath of SARS, several of such exploration studies have been conducted, but these studies did not include international comparisons across a range of different countries. These studies showed that the risk of SARS was perceived differently across the globe and was not directly linked to the proximity of the outbreak. Risk perception of SARS in some of the Asian countries was relatively low compared to risk perception in the USA [13-15] but similar to levels reported for The Netherlands [16]. One study focused on differences in psychosocial factors predicting preventive behavior in four affected regions [17]. Ji and colleagues compared optimism related to SARS in China and Canada and concluded that both groups demonstrated unrealistic optimism, while at the same time they were overly pessimistic about their own chances of getting infected [18]. A limited number of studies have looked at risk perception of avian influenza with different results varying from high perceived risks to low risk perception [19-22]. A Dutch study showed high levels of risk perception of avian influenza in case of an outbreak and indicated that almost $40 \%$ of respondents had taken some sort of precautionary measures [23].

There are few international comparative studies that analyze differences in perceived threat, risk perception, and efficacy beliefs between (infectious) diseases and conditions and differences between countries [24-27]. It is generally unknown whether risk perceptions of emerging infectious diseases are perceived in similar ways across countries. Because there was a large difference between how SARS has affected Southeast Asia and Europe, one might hypothesize that this would mean a higher risk perception of SARS and possibly other infectious diseases in countries in Southeast Asia. If international differences in risk perceptions of SARS exist, the question is whether such differences are specific for SARS, whether we see the same for risk perception of avian influenza (as most cases have also occurred in Southeast Asia), or whether they may indicate a more general trend in risk perceptions.

The present study explored perceived threat, risk perception, and efficacy beliefs related to SARS in random samples of the population of eight countries in Europe and Asia. To explore if country differences were specific for SARS, perceived threat, risk perception, and efficacy beliefs related to avian influenza and other (infectious) diseases were also investigated. This study had the following specific objectives:

- To study levels of perceived threat, vulnerability (or risk perception), severity and comparative vulnerability for SARS in Denmark, The Netherlands, Poland, Spain, the UK, China, Hong Kong, and Singapore;

- To compare perceived severity, vulnerability, and threat of SARS with other diseases and conditions, i.e., avian influenza, common cold, diabetes, HIV, high blood pressure, tuberculosis, food poisoning, and a heart attack;

- To study differences and associations between these factors across the eight countries and between Europe and Asia. 
Because data collection for the present study took place in the autumn of 2005 , i.e., 2 years after the SARS epidemic, it was not possible to collect information on specific precautionary behaviors. Furthermore, specific results on risk perception of avian influenza and related efficacy beliefs have been reported elsewhere [23].

\section{Methods}

Procedure and Respondents

Data were collected using computer-assisted telephone interviewing in the native languages by native speakers of each country, coordinated by a Dutch company that specializes in international telephone survey research, using random digit dialing (RDD). For the Asian countries, the Dutch company was assisted by an Asian agency. If unanswered, numbers were tried again up to five times and, when possible, call back appointments were made. Interviews were conducted from 20 September to 22 November 2005 in eight different countries, five in Europe representing regions in North, West, South, and East Europe (Denmark, The Netherlands, Great Britain, Spain, and Poland) and three regions in East Asia (Singapore, province of Guangdong China, and Hong Kong). In China, the survey was conducted in the province of Guangdong. During the period of data collection, no cases of SARS were reported. Respondents aged 18 to 75 years were eligible for participation.

\section{Questionnaire}

The questionnaire was based on a previously developed SARS risk perception questionnaire [16] and focused on risk perception and severity of SARS, avian influenza, and other (infectious) diseases, efficacy beliefs and use of information sources and took, on average, $16 \mathrm{~min}$ to complete. The questionnaire was first developed in English, translated into Dutch, and subsequently pretested in Great Britain and The Netherlands using cognitive interviewing. Further translations were made into Danish, Spanish, Polish, Mandarin, and Cantonese; all translations were conducted by professional translators and checked by native speakers, including members of the project team.

The questionnaire started with basic demographic questions, including urbanization and level of education (see Table 1 for categories). Respondents were then presented with the following diseases or conditions: diabetes, a common cold, HIV, high blood pressure, SARS, tuberculosis, heart attack, flu from a new virus, and food poisoning. These illnesses and conditions were included as these are both infectious and noninfectious diseases, some more common and familiar, and some with more serious consequences, thus giving a range of options for comparisons. For SARS and flu, the respondents first received a brief explanation (for SARS, "SARS is a severe acute breathing related illness caused by a previously unknown virus"; for flu, "A new type of flu virus can arise from avian flu, it causes serious illness and spreads easily in the population"). Respondents were then asked about:

1. Severity ("How serious (on a scale from 1 to 10 ) would it be for you if you got [disease] in the next year?");

2. Vulnerability ("How likely do you think it is that you will develop or contract a [disease] in the next year; very unlikely (1) to very likely (5));

3. Comparative vulnerability ("How likely do you think it is that you will develop or contract [disease] in the next year compared to other [women/men] of your age in [own country]; much less likely (1) to much more likely (5)).

The questionnaire continued with two questions focusing on knowledge of SARS (name symptoms, whether SARS is a communicable disease).

For SARS, flu from a new virus, and common cold, the following additional questions were included: response efficacy ["To what extent do you think people can take effective actions to prevent getting SARS/flu from a new virus/common cold in case of an outbreak"; outbreak was included for SARS and flu from a new virus; not at all (1) to very much (4)]; self-efficacy ["How confident are you that you can prevent getting SARS/flu from a new virus/ common cold in case of an outbreak"; not confident (1) to very confident (4)]. The order of these three diseases was chosen randomly by the computer. The questionnaire continued with questions on use of sources of information during the SARS outbreak, trust in these sources, and preferences for ways of communication during future outbreaks. Respondents where then presented with scenarios and asked about possible preventive actions. Results of this have been reported elsewhere [28]. The questionnaire concluded with some general background questions on perceived general health, perceived happiness, whether respondent had been vaccinated against influenza, and about employment status, education level, and religion. (The questionnaire is available online at http://www2.eur.nl/fgg/

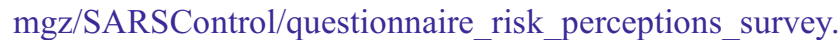
$\mathrm{htm}$.)

\section{Statistical Analysis}

Respondents indicating they never heard about SARS $(1.3 \%)$ were excluded from the analyses. Furthermore, "don't know" answers on the questions about risk percep- 
Table 1 Participation rates and distribution of general characteristics in the study population

\begin{tabular}{|c|c|c|c|c|c|c|c|c|c|c|c|}
\hline & $\begin{array}{l}\text { DNK } \\
(\%)\end{array}$ & $\begin{array}{l}\text { POL } \\
(\%)\end{array}$ & $\begin{array}{l}\text { NLD } \\
(\%)\end{array}$ & $\begin{array}{l}\text { GBR } \\
(\%)\end{array}$ & $\begin{array}{l}\text { ESP } \\
(\%)\end{array}$ & $\begin{array}{l}\mathrm{CHN} \\
(\%)\end{array}$ & $\begin{array}{l}\mathrm{HKG} \\
(\%)\end{array}$ & $\begin{array}{l}\text { SGP } \\
(\%)\end{array}$ & $\begin{array}{l}\text { Europe } \\
(\%)\end{array}$ & $\begin{array}{l}\text { Asia } \\
(\%)\end{array}$ & $\begin{array}{l}\text { Total } \\
(\%)\end{array}$ \\
\hline Total $n$ & 463 & 488 & 400 & 401 & 425 & 404 & 396 & 426 & 2,177 & 1,226 & 3,403 \\
\hline Total \% & 14 & 14 & 12 & 12 & 12 & 12 & 12 & 13 & 64 & 36 & 100 \\
\hline Participation rate & 58 & 81 & 44 & 21 & 34 & - & - & - & 40 & 13 & \\
\hline \multicolumn{12}{|l|}{ Gender } \\
\hline Male & 40 & 39 & 42 & 41 & 41 & 47 & 44 & 43 & 40 & 45 & 42 \\
\hline Female & 60 & 61 & 58 & 59 & 59 & 53 & 56 & 57 & 60 & 55 & 58 \\
\hline \multicolumn{12}{|l|}{ Age group } \\
\hline $18-30$ & 13 & 18 & 10 & 13 & 17 & 43 & 27 & 35 & 14 & 35 & 22 \\
\hline $31-45$ & 31 & 31 & 31 & 35 & 34 & 34 & 35 & 31 & 32 & 33 & 33 \\
\hline $44-60$ & 36 & 32 & 37 & 31 & 32 & 19 & 27 & 20 & 33 & 22 & 29 \\
\hline $61-75$ & 20 & 19 & 24 & 21 & 17 & 4 & 12 & 14 & 20 & 10 & 16 \\
\hline \multicolumn{12}{|l|}{ Area } \\
\hline City & 26 & 21 & 9 & 20 & 45 & 86 & 90 & 81 & 24 & 86 & 46 \\
\hline Town & 38 & 25 & 37 & 45 & 42 & 9 & 4 & 16 & 37 & 10 & 27 \\
\hline Village/countryside & 37 & 54 & 55 & 36 & 13 & 4 & 6 & 2 & 39 & 4 & 26 \\
\hline \multicolumn{12}{|l|}{ Education } \\
\hline Primary or lower & 17 & 8 & 5 & 2 & 22 & 4 & 13 & 3 & 11 & 7 & 9 \\
\hline Low & 31 & 22 & 28 & 20 & 9 & 19 & 20 & 11 & 22 & 16 & 20 \\
\hline Intermediate & 38 & 43 & 35 & 35 & 31 & 35 & 32 & 38 & 37 & 35 & 36 \\
\hline High & 13 & 28 & 32 & 43 & 38 & 42 & 35 & 48 & 30 & 42 & 34 \\
\hline
\end{tabular}

DNK Denmark, $P O L$ Poland, NLD The Netherlands, ESP Spain, CHN China, HKG Hong Kong, SGP Singapore

tion were treated as missing values and, therefore, also excluded from the analysis. On average, $4.4 \%$ of respondents did not know how to rate SARS severity and $4.3 \%$ could not rate their vulnerability to SARS.

For the different countries, mean scores and standard deviations (SD) were calculated for severity, risk perception, perceived threat (see below), and comparative vulnerability of eight different diseases or conditions. In line with the Protection Motivation Theory, one measure was defined as "perceived threat"; it was constructed by multiplication of the measures of perceived severity (scale 1-10) and vulnerability (in case of an outbreak in the country for SARS and flu from a new flu virus; scale 1-5). To make the scores comparable, the severity score was first divided by two. To normalize the skewed distribution of the new variable, a square root transformation was performed that resulted in a measure of perceived threat on a scale from 1 (low) to 5 (high). A SARS knowledge score (scale 0-2) was calculated based on whether the respondent could name a symptom of SARS and whether the respondent knew SARS was a communicable disease. Differences in background characteristics (gender, age group, area, and level of education) and risk perceptions between the samples in Europe and Asia were explored with chi-square tests or (paired) Student's $t$ tests, of which the $p$ value and the effect size $r$ are reported. An $r$ below 0.30 indicates low effect size, $0.30-0.50$ indicates medium effect sizes, and higher than 0.50 indicates large effect size.
To test for important correlates of SARS-related risk perceptions, four multiple linear hierarchical regression models were applied with perceived severity, vulnerability, threat, and comparative vulnerability as dependent variables. The independent variables were included in blocks with country (dummy coded) in the first block, sex, age, highest education, and urbanization in the second block, and the amount of information during the SARS outbreak and the SARS knowledge score in the last block. As we did not want to choose one country as a reference group, we ran the models by leaving out the intercept. In doing so, the regression coefficients for the countries do not represent the difference in mean compared to the reference group but the actual (corrected) mean value of the respective dependent variable. The $R^{2}$, a measure of the proportion of variance in the dependent variable that is explained by the independent variables in the model, is given for each hierarchical step in the models. The models were applied to the total population and the model for perceived threat was also applied to the separate countries.

\section{Results}

Response and General Characteristics

In the European countries, $16 \%$ of the numbers created by RDD were nonexistent and $26 \%$ of the numbers could not 
be reached after five times. Of the people eligible for participation, $40.2 \%$ completed the interview and 59.8\% refused. Participation rates varied from $21.3 \%$ in the UK to $81.1 \%$ in Poland (see Table 1). For the interviews conducted by the Asian agency, no response rates are available. In total, 3,436 respondents were interviewed.

Data on background variables in the different participating countries are provided in Table 1. Most respondents in all countries were female ( $58 \%$ in the total group). European respondents were significantly older than Asian respondents $(p<0.001, r=0.27)$. Substantially more respondents in Asia lived in a city, as both Hong Kong and Singapore were included $(p<0.001, r=0.56)$. Asian respondents were higher educated than European respondents $(p<0.001, r=0.014)$.

Risk Perception and Severity of SARS and Other Diseases

SARS was rated as the third most severe problem among the diseases and conditions included, HIV as the most serious problem and common cold as the least serious (see Table 2). Compared to flu from a new flu virus, SARS was rated more serious in all countries (overall $=8.3$ versus 7.0 (scale 1-10), $p<0.001, r=0.47$; country-specific test results not shown). Perceived vulnerability, risk perception, for common cold was the highest, 3.8, and for HIV the lowest, 1.4 (scale 1-5). For SARS, the risk perception levels differed in case of an outbreak in or outside the country. It was among the highest with 2.7 in case of an outbreak in the country, while in case of an outbreak outside the country it was $2.1(p<0.001, r=0.44)$. The vulnerability for an outbreak of flu from a new flu virus was higher than for SARS both in case of outbreak inside the country (3.1 versus $2.7, p<0.001, r=0.31)$ and outside the country (2.9 versus $2.1, p<0.001, r=0.48)$. This finding was true for all countries (separate test results not shown).

Perceived threat of SARS in case of an outbreak in the country was among the highest of the diseases with a mean score of 3.2 (scale 1-5); perceived threat of HIV (2.4) and a common cold (2.1) were the lowest. Perceived threat of SARS and flu from a new flu virus in case of an outbreak were similar in most countries, but in Denmark, China, and Hong Kong, SARS was perceived more threatening than flu from a new flu virus $(p<0.001, r=0.23 ; p<0.001, r=0.25$; and $p=0.004, r=0.15$, respectively).

The level of perceived threat varied across countries. Perceived threat of SARS was the highest in Poland and the lowest in Singapore. In Fig. 1, the results of perceived threat of SARS, flu from a new virus, high blood pressure, and diabetes are presented. Although levels of perceived threat varied between countries, the pattern of perceived threat differences between the different diseases and conditions was the same in all countries with perceived threat of SARS and avian flu being the highest and diabetes the lowest.

The comparative vulnerability of SARS in case of an outbreak outside the country was 2.6 (scale 1-5), indicating that that people thought it slightly less likely that they would contract SARS compared to the average other (Table 2). The much lower value for $\operatorname{HIV}(1.6, p<0.001$, $r=0.65$ ) indicates that participants, on average, thought it much less likely to contact HIV compared to other people of the same age and gender.

\section{Comparison Europe-Asia}

SARS was perceived as a more severe problem in Europe, 8.42, compared to Asia, 8.02 (on a scale of $1-10[p<$ $0.00005, r=0.09])$ ), while Asia perceived a higher vulnerability, 2.54 (Europe, 1.86; $p<0.00005, r=0.29$; see Table 3$)$. For flu from a new flu virus, perceived severity was higher in Europe, 7.06 to 6.74 in Asia $(p<0.0005, r=$ 0.06 ) as was perceived vulnerability, 3.16 to 2.97 ( $p<$ $0.00005, r=0.08$ ). In comparing Europe to Asia, there is not one pattern for all diseases, some are perceived more severe in Europe (heart attack, HIV), others in Asia (food poisoning, common cold) nor is there for perceived vulnerability.

\section{Knowledge and Efficacy Beliefs}

Of the respondents in the Asian countries, more than $80 \%$ could name symptoms of SARS; this percentage was just over $40 \%$ in European countries. The proportion who knew SARS was a communicable disease varied between $62 \%$ in Spain and $88 \%$ in Denmark. The mean knowledge score was 1.2 (range $0-2)$ in Europe and 1.7 in Asia $(p<0.001, r=0.69)$.

Self-efficacy was lower than response efficacy for both SARS and a common cold in all countries, but the difference was larger for SARS. Both response efficacy and selfefficacy for SARS were higher in the Asian countries compared to the European countries $(p<0.001, r=0.28$ and $p<0.001, r=0.40$, respectively; see Fig. 2).

\section{Linear Regression Model}

The regression models for perceived severity, vulnerability, threat, and comparative vulnerability for all countries combined are presented in Table 4. Country was significantly associated with perceived threat, vulnerability, severity, and comparative vulnerability. Besides country, a higher perceived severity of SARS was significantly associated with female gender, lower level of education, and a higher SARS knowledge score. A higher perceived vulnerability for SARS was significantly associated with lower level of education. 
Table 2 Mean scores and standard deviations (SD) of severity, vulnerability, and perceived threat of eight different diseases and conditions, $N=3,436$

\begin{tabular}{|c|c|c|c|c|c|c|c|c|}
\hline \multirow[t]{2}{*}{ Disease } & \multicolumn{2}{|c|}{$\begin{array}{l}\text { Severity } \\
\text { (scale } 1-10)\end{array}$} & \multicolumn{2}{|c|}{$\begin{array}{l}\text { Vulnerability } \\
\text { (scale 1-5) }\end{array}$} & \multicolumn{2}{|c|}{$\begin{array}{l}\text { Perceived threat }{ }^{\mathrm{a}} \\
\text { (scale 1-5) }\end{array}$} & \multicolumn{2}{|c|}{$\begin{array}{l}\text { Comparative vulnerability } \\
\text { (scale } 1-5 \text { ) }\end{array}$} \\
\hline & Mean & SD & Mean & $\mathrm{SD}$ & Mean & $\mathrm{SD}$ & Mean & SD \\
\hline SARS. outbreak in country ${ }^{\mathrm{b}}$ & 8.3 & 2.1 & 2.7 & 1.2 & 3.2 & 0.9 & 2.6 & 1.0 \\
\hline Heart attack & 8.4 & 2.1 & 2.5 & 1.2 & 3.1 & 0.9 & 2.5 & 1.1 \\
\hline Flu from new virus. outbreak in country ${ }^{\mathrm{b}}$ & 6.9 & 2.5 & 3.1 & 1.2 & 3.1 & 0.9 & 2.8 & 1.0 \\
\hline Flu from a new flu virus ${ }^{\mathrm{b}}$ & 6.9 & 2.5 & 2.9 & 1.2 & 3.0 & 0.9 & 2.7 & 1.0 \\
\hline SARS. outbreak outside country ${ }^{\mathrm{b}}$ & 8.3 & 2.1 & 2.1 & 1.1 & 2.8 & 0.9 & 2.2 & 1.0 \\
\hline High blood pressure & 6.4 & 2.2 & 2.4 & 1.2 & 2.7 & 0.9 & 2.4 & 1.1 \\
\hline Tuberculosis & 7.3 & 2.3 & 2.0 & 1.0 & 2.6 & 0.8 & 2.1 & 0.9 \\
\hline Food poisoning & 5.6 & 2.5 & 2.6 & 1.2 & 2.6 & 0.9 & 2.4 & 1.0 \\
\hline Diabetes & 6.8 & 2.5 & 2.0 & 1.1 & 2.5 & 0.9 & 2.2 & 1.0 \\
\hline HIV & 9.1 & 2.1 & 1.4 & 0.8 & 2.4 & 0.7 & 1.6 & 0.8 \\
\hline Common cold & 2.8 & 2.1 & 3.8 & 1.2 & 2.1 & 0.9 & 3.0 & 1.0 \\
\hline
\end{tabular}

${ }^{\text {a }}$ Perceived threat is the square root of the multiplication of severity/2 and vulnerability. Diseases are ranked by perceived threat score

${ }^{\mathrm{b}}$ Severity of SARS and flu from a new virus was asked in general. The mean score is given in the table for both situations (outbreak in or outside country)

All the variables that were significantly associated with severity and vulnerability were also significantly associated with perceived threat. Comparative vulnerability was significantly associated with gender and amount of information. Comparative vulnerability in women was lower than in men and lower in respondents that received more information about SARS. The models for each outcome variable explained less than $10 \%$ of the variance (Table 5). The proportion of the variance explained by country was higher than that for the other potential correlates in the models.

Analysis per country (Table 6) showed that perceived threat of SARS was higher in respondents with lower levels of education in Poland, Great Britain, and Spain, while it was higher among the higher educated in Singapore. Singapore was the only country where age was independently associated with perceived threat. Level of urbanization was a significant correlate in Poland only with living in less urban areas associated with a lower threat. In The Netherlands and Denmark, perceived threat was higher in respondents who received higher amounts of information about SARS, and in Great Britain, it was higher in respondents with a higher knowledge score. The model for the total population explained $7.5 \%$ of variance of which $5.9 \%$ was accounted for in a model with only the country variable (Table 5). In the separate models by country, the explained variance was less than $5 \%$ in all countries.

\section{Discussion}

The present study shows that perceived threat of SARS in case of an outbreak in the country was higher than that of other diseases and conditions included in this study. Perceived vulnerability of SARS was at an intermediate level compared to other diseases while perceived severity was high. Perceived threat for SARS varied between countries in Europe and Asia with perceived severity higher in Europe and perceived vulnerability higher in Asia. Perceptions of vulnerability compared to other people for SARS was relatively small and comparable to other diseases. Response efficacy and self-efficacy for SARS were higher in Asia compared to Europe.

Our study has several limitations, especially related to the means of data collection. Firstly, the response rate varied substantially between countries from $21.3 \%$ to $81.1 \%$ with low response rates in the participating Asian

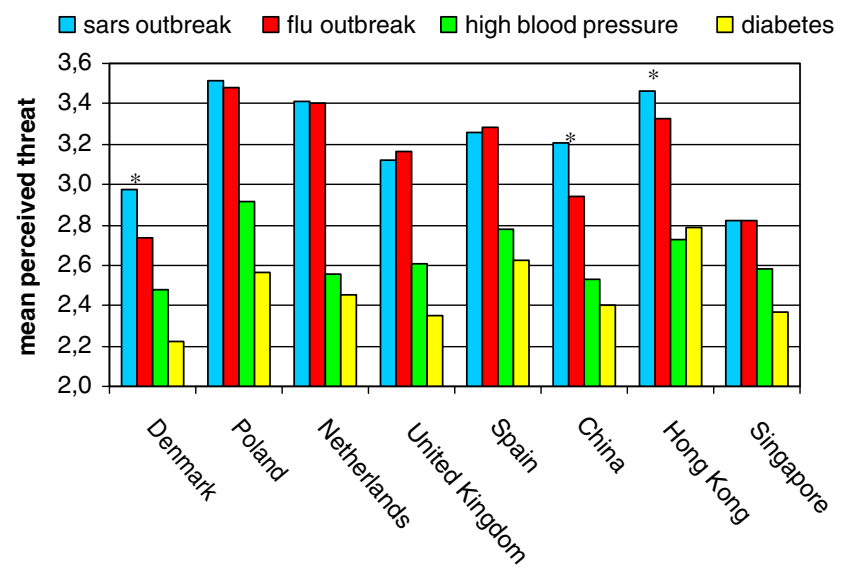

* difference in mean perceived threat between SARS and flu is statistically significant

Fig. 1 Mean perceived threat of SARS and flu from a new flu virus in case of an outbreak, high blood pressure and diabetes by country. The asterisk indicates that the difference in mean perceived threat between SARS and flu is statistically significant 
Table 3 Mean scores of severity and vulnerability for different diseases and conditions compared for Europe and Asia

\begin{tabular}{|c|c|c|c|c|c|c|c|c|}
\hline \multirow[t]{2}{*}{ Disease } & \multicolumn{4}{|c|}{ Severity (scale 1-10) } & \multicolumn{4}{|c|}{ Vulnerability (scale 1-5) } \\
\hline & Europe & Asia & Difference & $T$ value $^{\mathrm{a}}$ & Europe & Asia & Difference & $T$ value $^{\mathrm{a}}$ \\
\hline SARS, outbreak outside country ${ }^{\mathrm{b}}$ & 8.42 & 8.02 & 0.40 & $4.8^{* * *}$ & 1.86 & 2.54 & -0.68 & $4.8^{* * *}$ \\
\hline SARS, outbreak in country ${ }^{\mathrm{b}}$ & 8.42 & 8.02 & 0.40 & $4.8^{* * *}$ & 2.69 & 2.70 & -0.01 & -0.3 \\
\hline Flu from a new flu virus ${ }^{\mathrm{b}}$ & 7.06 & 6.74 & 0.32 & $3.6^{* *}$ & 2.89 & 2.82 & 0.07 & 1.5 \\
\hline Flu from new virus, outbreak in country ${ }^{\mathrm{b}}$ & 7.06 & 6.74 & 0.32 & $3.6^{* *}$ & 3.16 & 2.97 & 0.19 & $4.5 * * *$ \\
\hline Heart attack & 8.87 & 7.45 & 1.42 & $18.2^{* * *}$ & 2.53 & 2.36 & 0.17 & $3.8^{* *}$ \\
\hline High blood pressure & 6.41 & 6.48 & -0.07 & -0.9 & 2.45 & 2.36 & 0.10 & 2.1 \\
\hline Tuberculosis & 7.60 & 6.66 & 0.94 & $10.5^{* * *}$ & 1.88 & 2.18 & -0.30 & $-7.7 * * *$ \\
\hline Food poisoning & 5.46 & 5.80 & -0.34 & $-3.7 * *$ & 2.56 & 2.71 & -0.14 & $-3.4^{*}$ \\
\hline Diabetes & 6.88 & 6.59 & 0.28 & $3.1^{*}$ & 1.91 & 2.16 & -0.24 & $-6.1 * * *$ \\
\hline HIV & 9.41 & 8.48 & 0.93 & $10.9 * * *$ & 1.36 & 1.46 & -0.09 & $-3.3 *$ \\
\hline Common cold & 2.45 & 3.52 & -1.07 & $-13.9 * * *$ & 3.86 & 3.58 & 0.28 & $6.9 * * *$ \\
\hline
\end{tabular}

${ }^{*} p<0.0025, * * p<0.0005, * * * p<0.00005$

a To adjust for multiple testing, the significance level was divided by the number of comparisons (20) using the Bonferroni adjustment

${ }^{\mathrm{b}}$ Severity of SARS and flu from a new virus was asked in general. The mean score is given in the table for both situations (outbreak in or outside country)

countries in particular. This may have led to nonrepresentative samples, and the differences in response rates may partly explain the reported differences in risk perceptions and other variables. These differences in response rates and the low rates in some of the participating countries limit the generalizability of our data, and the results should, therefore, be interpreted with caution.

Secondly, because of the lack of an existing validated questionnaire for perceived threat and risk perception of infectious diseases suitable for telephone administration in large samples, the questionnaire was specifically developed for the project reported in this paper based upon an earlier questionnaire used during the SARS outbreak [16]. Our study design, aiming to include a large number of respondents from a range of different countries and regions, using telephone surveying as the means of data collection, combined with the financial and time pressure restraints, enabled the inclusion of only a limited number of items per construct. This may have reduced the reliability of our measures, especially toward possible underlying cultural differences in constructs. Furthermore, extensive pretesting of the survey questionnaire with cognitive interviewing was restricted to two European countries. We, therefore, do not know whether all concepts used were understood in the same way in all participating countries. On the other hand, we did contextualize our risk perception questions by including a setting (in case of an outbreak), time frame (next 12 months), and focusing on the risk of the individual (instead of population) - all issues known to be important for measuring risk percep-

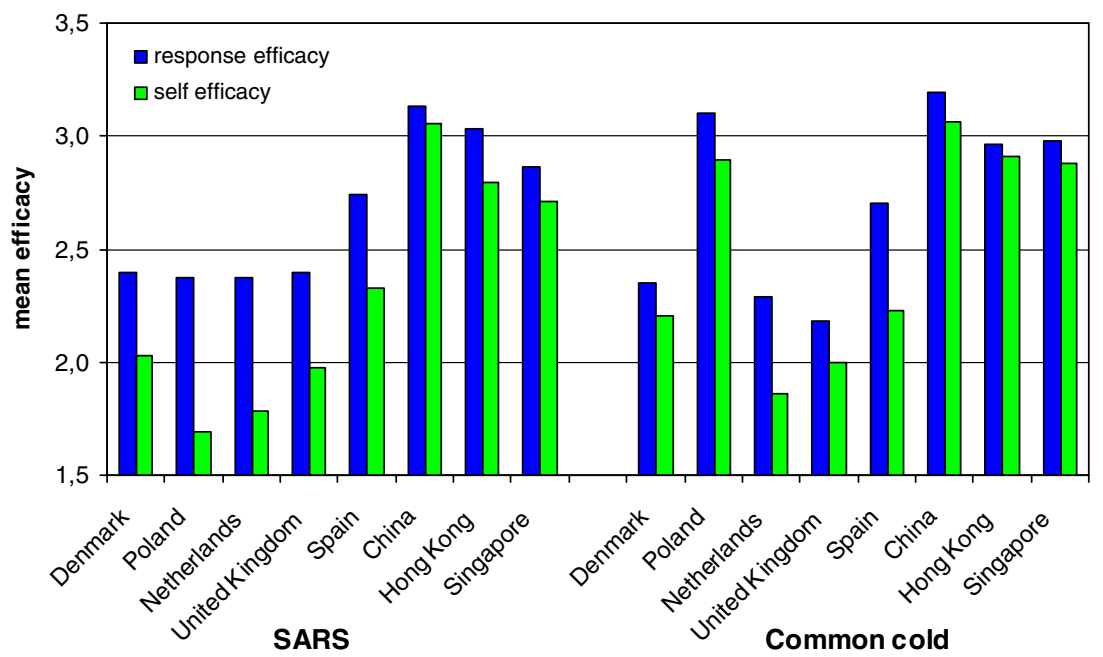

Fig. 2 Mean response efficacy and self-efficacy for SARS in case of an outbreak and a common cold by country 
Table 4 Correlates of perceived SARS severity, vulnerability, perceived threat and comparative vulnerability; unstandardized regression coefficients (B) and $p$ values derived from linear regression analyses $(\mathrm{n}=3064)$

\begin{tabular}{|c|c|c|c|c|c|c|c|c|}
\hline & \multicolumn{2}{|c|}{ Seriousness } & \multicolumn{2}{|c|}{ Vulnerability } & \multicolumn{2}{|l|}{ Threat } & \multicolumn{2}{|c|}{ Vulnerability compared to other people } \\
\hline & $B$ & $p$ & $B$ & $p$ & $B$ & $p$ & $B$ & $p$ \\
\hline Country $^{\mathrm{a}}$ & & $<0.001$ & & $<0.001$ & & $<0.001$ & & $<0.001$ \\
\hline Denmark & 8.40 & & 2.32 & & 2.95 & & -0.76 & \\
\hline Poland & 8.16 & & 3.23 & & 3.50 & & -0.25 & \\
\hline The Netherlands & 8.23 & & 2.96 & & 3.37 & & -0.30 & \\
\hline Great Britain & 8.05 & & 2.68 & & 3.11 & & -0.55 & \\
\hline Spain & 7.94 & & 2.83 & & 3.23 & & -0.29 & \\
\hline China & 8.09 & & 2.70 & & 3.14 & & -0.78 & \\
\hline Hong Kong & 8.01 & & 3.01 & & 3.34 & & -0.47 & \\
\hline Singapore & 6.83 & & 2.57 & & 2.73 & & -0.97 & \\
\hline Sex (male is the reference) & 0.57 & 0.000 & 0.07 & 0.090 & 0.17 & 0.000 & 0.08 & 0.014 \\
\hline Age & 0.00 & 0.237 & 0.00 & 0.875 & 0.00 & 0.303 & 0.00 & 0.300 \\
\hline Highest education & -0.14 & 0.001 & -0.08 & 0.001 & -0.07 & 0.000 & -0.01 & 0.669 \\
\hline Urbanization & -0.07 & 0.118 & -0.02 & 0.365 & -0.04 & 0.059 & -0.02 & 0.261 \\
\hline Amount of info during SARS outbreak & 0.05 & 0.155 & 0.03 & 0.188 & 0.03 & 0.090 & 0.04 & 0.019 \\
\hline SARS knowledge score & 0.16 & 0.010 & 0.05 & 0.170 & 0.07 & 0.016 & 0.04 & 0.134 \\
\hline
\end{tabular}

${ }^{\mathrm{a}}$ The $p$ value for country stands for the overall significance of the differences between countries

tions, although not always included in studies on risk perceptions [7].

Data collection took place in autumn 2005, 2 years after the end of the SARS epidemic. This may have influenced the recollection of knowledge and use of information sources during the SARS epidemic. However, the study consortium responsible for the present study also conducted qualitative explorations of risk perceptions, efficacy beliefs, and precautionary actions among Chinese populations in the UK and The Netherlands, showing similar results (Jiang et al., submitted for publication).

The present study also has its strengths. It is among the first large-scale comparative studies into perceived threat and risk perception of emerging infectious diseases, and in fact, unique in the number of countries represented. Perceived threat for SARS, as well as avian influenza, were among the highest and at the same level as for, for example, a heart attack. This indicates that these potential problems were taken very seriously by the general public.

Because few comparative studies into perceived threat of SARS and other newly emerging infectious diseases have been conducted, it is difficult to interpret the differences between countries and continents. Comparing our results with data from several earlier studies on risk perception of SARS in the USA, Canada, The Netherlands, Singapore and Hong Kong has its limitations, as these studies were done in 2003 during the SARS epidemic, whereas in our study, we asked respondents to envisage a new outbreak [13-16]. For example, in 2003, risk perception of SARS in some of the Asian countries was relatively low compared to risk perception in the USA. Ji et al., in their study on optimism across cultures, have pointed out that unrealistic optimism concerning SARS was higher among Chinese than among Canadians [18]. They interpreted this being in line with the Chinese and East Asians in general holding a cyclical perception of events, so that a negative event may be seen as antecedent to a positive outcome.

The higher level of severity of some diseases in Europe (SARS, flu from a new virus, HIV, tuberculosis) may indicate that more unfamiliar diseases are perceived more severe. The higher perceived vulnerability for some diseases (SARS, tuberculosis, HIV) in Asia may be based

Table $5 R^{2}$ of the different steps in the linear regression models and significance in $F$ change

\begin{tabular}{|c|c|c|c|c|c|c|c|c|}
\hline & \multicolumn{2}{|c|}{ Seriousness } & \multicolumn{2}{|c|}{ Vulnerability } & \multicolumn{2}{|l|}{ Threat } & \multicolumn{2}{|c|}{ Comparative vulnerability } \\
\hline & $R^{2}$ & $p$ & $R^{2}$ & $p$ & $R^{2}$ & $p$ & $R^{2}$ & $p$ \\
\hline$R^{2}$ step 1 & 0.041 & 0.000 & 0.053 & 0.000 & 0.059 & 0.000 & 0.062 & 0.000 \\
\hline$R^{2}$ step 2 & 0.064 & 0.000 & 0.057 & 0.008 & 0.072 & 0.000 & 0.064 & 0.051 \\
\hline$R^{2}$ step 3 (full model) & 0.067 & 0.004 & 0.058 & 0.095 & 0.075 & 0.004 & 0.067 & 0.007 \\
\hline Adjusted $R^{2}$ full model & 0.063 & & 0.054 & & 0.072 & & 0.063 & \\
\hline
\end{tabular}


upon the fact that these are indeed more prevalent in these regions.

The observation that, compared to Europe, efficacy beliefs for SARS were more positive in Asia and that people felt more able to control SARS, may be explained in the same way. Alternatively, it may also be that the more direct and closer experience with the disease in Asia and the experience of outliving and overcoming the outbreak have increased self-efficacy and response efficacy beliefs in Asia. Preventive measures in Asia were also more visible and might have been more reassuring to the public [2]. Also, efficacy beliefs related to a common cold and flu from a new virus were higher in Asian countries where the latter may be explained by the fact that, despite the first cases of avian influenza among humans in Asia already reported in 2003, this has not resulted in a larger outbreak [22].

The lower level of risk perception in Denmark may reflect part of a Scandinavian tendency to perceive risks lower than in other countries [29]. This result is also in line with a lower risk perception of SARS among Finns compared to Dutch $[24,30]$. One of the explanations for this tendency is that the media in Scandinavia appear to report more about risks abroad with less attention to risk inside the country [29]. However, we need to interpret the differences between countries with care because cognitive constructs such as risk perceptions are not necessarily interpreted in the same way in different cultures [31]. Indeed, the data of our study on comparison of risk perceptions for various diseases show that the relative risk perceptions for these diseases, i.e., the order of levels of risk perceptions, are rather consistent across countries. This may indicate that differences between countries in absolute risk perception levels for specific diseases or conditions may reflect cultural differences in the way survey questions are answered rather than real differences in risk perceptions. Voeten et al. [32], in their study on risk perception and efficacy beliefs among Chinese communities in the UK and The Netherlands, have shown that efficacy beliefs of Chinese living in the UK and The Netherlands were comparable to those of native UK and Dutch respondents. This may indicate that country of residence, perhaps because of country-specific public health systems and media coverage, may be more important than ethnicity or country and culture of origin. Because country appears to be a relevant correlate of SARS-related risk perceptions in the multivariate analyses, further research is needed to explain these country differences.

The results on comparative vulnerability indicate that envisioning an outbreak might make a difference; when respondents were asked to compare their personal risk to that of comparable others, the optimistic bias was lower in case of an outbreak. Such a situation is characterized by 
less control, which is associated with less optimism [33, 34]. The notion that, for an outbreak, risks were perceived to be more evenly distributed, and thus they seemed to be less prone to an optimistic bias, may offer starting points for public interventions. Such interventions should certainly also focus on increasing self-efficacy, especially in the European countries, because low self-efficacy may lead to lack of protection motivation.

Perceived threat of SARS and flu from a new flu virus in case of an outbreak was similar in most countries. However, the level of severity for SARS was higher than for flu from a new virus, while vulnerability for flu from a new virus was higher than for SARS in all countries. One explanation might be that SARS is a more unfamiliar disease for most people compared to flu. It indicates that people do perceive various aspects of risk perceptions differently for different emerging infectious diseases and that risk communication should thus be disease- and perception-specific.

Perceived threat for emerging infectious diseases such as SARS and avian influenza were amongst the highest rated in the present study, especially in case of an outbreak. From a public health perspective, this offers a good starting point for risk communication and precautionary actions. It also asks for realistic risk communications to put the risks for SARS and other emerging infectious diseases into the perspective of global health risks to prevent fuelling unnecessary panic [35].

Acknowledgements This work was done as part of SARSControl: Effective and Acceptable Strategies for the Control of SARS and New Emerging Infections in China and Europe, a European Commission project funded within the Sixth Framework Programme, Thematic Priority Scientific Support to Policies, contract no. SP22-CT-2004-003824.M.

Open Access This article is distributed under the terms of the Creative Commons Attribution Noncommercial License which permits any noncommercial use, distribution, and reproduction in any medium, provided the original author(s) and source are credited.

\section{References}

1. Abraham T. Twenty-first century plague. The story of SARS. Hong Kong: Hong Kong University Press; 2004.

2. Smith RD. Responding to global infectious diseases outbreaks: lessons from SARS on the role of risk perception, communication and management. Soc Sci Med. 2006;63:3113-23.

3. Bell DM, World Health Organization Working Group on Prevention of International and Community Transmission of SARS. Public health interventions and SARS spread, 2003. Emerging infectious diseases [serial on the Internet]. Nov. http://www.cdc.gov/ncidod/ EID/vol10no11/04-0729.htm. Accessed 1 April 2007.

4. World Health Organization Writing Group. Non-pharmaceutical interventions for pandemic influenza, international measures. Emerging infectious diseases [serial on the Internet]. Jan. http:// www.cdc.gov/ncidod/EID/vol12no01/05-1370.htm (2006a). Accessed 1 March 2007.
5. World Health Organization Writing Group. Nonpharmaceutical interventions for pandemic influenza, national and community measures. Emerging infectious diseases [serial on the Internet]. Jan. http://www.cdc.gov/ncidod/EID/vol12no01/05-1371.htm (2006b). Accessed 1 March 2007.

6. Bosman A, Du Ry van Beest Holle M, Conyn-van Spaendonck MAE, Koopmans MPG. Compliance among poultry workers to infection control measures during a large epizootic of avian influenza in commercial poultry farms in The Netherlands (no. 630940001/2004). Bilthoven: RIVM Instituut voor Psychotrauma.; 2004.

7. Brewer NT, Chapman GB, Gibbons FX, Gerard M, McCaul KD, Weinstein ND. A meta-analysis of the relationship between risk perception and health behavior: the example of vaccination. Health Psychol. 2007;26 2:136-45.

8. Rogers RW. Cognitive and physiological processes in fear appeals and attitude change: a revised theory of protection motivation. New York: Guilford; 1983.

9. Sjoberg L. Factors in risk perception. Risk Anal. 2000;20 1:1-11.

10. Weinstein ND. The precaution adoption process. Health Psychol. 1988;7 4:355-86.

11. Slovic P. Perception of risk. Science. 1987;236:280-85.

12. Weinstein N. Why it won't happen to me: perceptions of risk factors and susceptibility. Health Psychol. 1984;3:431-57.

13. Blendon R, Benson JM, DesRoches CM, Raleigh E, Taylor-Clark K. The public's response to severe acute respiratory syndrome in Toronto and the United States. Clin Infect Dis 2004;38:925-31.

14. Lau J, Yang X, Tsui H, Kim JH. Monitoring community responses to the SARS epidemic in Hong Kong: from day 10 to day $62 . \mathrm{J}$ Epidemiol Community Health. 2003;57:864-70.

15. Leung G, Lam TH, Ho LM, Ho SY, Chan BH, Wong IO, et al. The impact of community psychological responses on outbreak control for severe acute respiratory syndrome in Hong Kong. J Epidemiol Community Health. 2003;57:857-63.

16. Brug J, Aro AR, Oenema A, De Zwart O, Richardus JH, Bishop GD. SARS risk perception, knowledge, precautions, and information sources, the Netherlands. Emerg Infect Dis. 2004;10 8:1486-9.

17. Cheng C, Ng A-K. Psychosocial factors predicting SARSpreventive behaviors in four major SARS-affected regions. J Appl Soc Psychol. 2006;36 1:222-47.

18. Ji L, Zhang Z, Usborne E, Guan Y. Optimism across cultures: in response to the severe acute respiratory syndrome outbreak. Asian J Soc Psychol. 2004;7:25-34.

19. Abbate R, Di Giuseppe G, Marinelli P, Angelillo IF. Knowledge, attitudes, and practices of avian influenza, poultry workers. Emerg Infect Dis. 2006;2 11:1762-4.

20. Fielding R, Lam WWT, Ho EYY, Lam TH, Hedley AJ, Leung GM. Avian influenza risk perception, Hong Kong. Emerging infectious diseases [serial on the Internet]. May. http://www. cdc.gov/ncidod/EID/vol11no05/04-1225.htm (2005). Accessed 1 March 2007.

21. Gupta R, Toby M, Bandopadhyay G, Cooke M, Gelb D, NguyenVan-Tam JS. Public understanding of pandemic influenza, United Kingdom. Emerg Infect Dis. 2006;12 10:1620-21.

22. De Zwart O, Veldhuijzen IK, Elam G, Aro AR, Abraham T, Bishop GD, et al. Avian influenza risk perception. Europe and Asia. Emerg Infect Dis 2007a;13 2:288-91.

23. De Zwart O, Veldhuijzen I, Richardus JH, Brug J. Risicoperceptie van infecties van mensen door het vogelgriepvirus in Nederland. TSG. 2007b;85 2:30-5.

24. Vartti A-M, Oenema A, Schreck M, Uutela A, de Zwart O, Brug J, et al. SARS knowledge, perceptions, and behaviors: a comparison between Finns and the Dutch during the SARS Outbreak in 2003. Int J Behav Med. doi:10.1007/s12529-008-9004-6.

25. Chang ED, Asawaka K. Cultural variations in optimistic bias: do Easterns really expect the worst and Westerns really expect the 
best when predicting future life events? J Pers Soc Psychol. 2001;81 3:476-91.

26. Chang ED, Asawaka K. Cultural variations on optimistic and pessimistic bias for self versus a sibling: is there evidence for selfenhancement in the West and for self-criticism in the East when the referent group is specified. J Pers Soc Psychol. 2003;84 3:569-81.

27. Renn O, Rohrmann B. Cross-cultural risk perception: a survey of empirical studies. Dordrecht: Kluwer; 2000.

28. Sadique MZ, Edmunds WJ, Smith RD, Meerding WJ, de Zwart O, Brug J, et al. Precautionary behavior in response to perceived threat of pandemic influenza. Emerging infectious diseases [serial on the Internet]. September. http://www.cdc.gov/EID/content/13/ 9/1307.htm (2007). Accessed 30 August 2007.

29. Mullet E, Lazreg C, Candela C, Neto F. The Scandinavian way of perceiving societal risks. J Risk Res. 2005;8 1:19-30.

30. Aro A, Aalto A-M, Oenema A, Brug J, De Zwart O, Turtiainen P, et al. Risk perception, information needs, and risk communication related to SARS. Eur J Public Health. 2005;15 suppl 1:70-1.
31. Luszczynska A, Scholz U, Schwarzer R. The general self-efficacy scale: multicultural validation studies. J Psychol. 2005;139 5: 439-57.

32. Voeten HACM, de Zwart O, Veldhuijzen IK, Yuen C, Jiang X, Elam G, et al. Sources of information and health beliefs related to SARS and avian influenza among Chinese communities in the United Kingdom and the Netherlands, compared to the general population in these countries. Int J Behav Med. doi:10.1007/ s12529-008-9006-4.

33. Pidgeon NF, Kasperson R, Slovic P. The social amplification of risk and risk communication. Cambridge, UK: Cambridge University Press; 2003.

34. Poortinga W, Bickerstaff K, Langford I, Niewöhner J, Pidgeon N. The British 2001 food and mouth crisis: a comparative study of public risk perceptions, trust, beliefs about government policy in two communities. J Risk Res. 2004;7:73-90.

35. Bonneux L, Van Damme W. An iatrogenic pandemic of fear. $\mathrm{Br}$ Med J. 2006;332 7544:786-8. 